\title{
Experimental dental caries in the albino rat
} The production of carious lesions in animals maintained on a finely
powdered purified diet containing $67 \%$ sucrose

\author{
By R. L. HARTLES, F. E. LAWTON AND G. L. SLACK \\ School of Dental Surgery, University of Liverpool
}

(Received 6 February 1956)

As far as we know, a caries-susceptible colony of rats has not hitherto been reared in this country. We were fortunate to receive a few animals from the stock maintained at the Harvard School of Dental Medicine. This colony has been produced over a number of years and is susceptible to the development of dental caries (Sognnaes, 1948; Shaw, 1950). All our rats were the descendants of four pairs of Harvard animals and have been multiplied by random mating. Brother-sister mating was not used. The colony is therefore more properly described as a caries-susceptible 'stock' rather than a 'strain'.

In considering experimental rat caries it is important to distinguish between the types of the disease known to occur in this animal. Hoppert, Webber \& Canniff (1932) found that a diet containing coarsely ground maize (HWC diet) leads to the production of dental caries in their rats. If the maize was finely milled to pass a 60-mesh sieve and then incorporated in the diet no caries resulted. Cox, Dodds, Levin \& Hodge (1948) showed that, after an initial period on the HWC diet, a high intake of sucrose $(67 \%$ of the diet) causes an increased rate of progression of caries, but that a high level of sugar in the diet of animals that had not previously received the HWC diet does not lead to the production of caries. As a result of these experiments they concluded that, in their animals, caries is initiated by the fracturing of the enamel owing to the impaction of coarse maize particles in the occlusal fissures of the rat molars. King (1935) had previously put forward this view, but he studied only relatively few rats. Cox et al. (1948) believed that the high-sugar diet encouraged the progression of the disease in their animals but did not initiate it. This type of experimental caries is generally termed 'fracture' caries.

However, McClure (1945), Sognnaes (1948) and Shaw (1950) have described carious lesions in rats receiving a finely powdered diet containing $67 \%$ sucrose similar to that used for producing caries in the cotton rat (Shaw, Schweigert, McIntire, Elvehjem \& Phillips, 1944). The experiments of Sognnaes (1948) show that, if rats are placed on the high-sugar diet at weaning, a mild caries develops. If the mother is given the sugar diet at parturition the severity of tooth decay in the offspring increases. The susceptibility to caries is greatest in the offspring of animals placed on the sugar diet throughout gestation and lactation.

The lesions described by the above workers are of the occlusal type originating in the deep fissures of the rat molars. More recently, Stephan (195I) and McClure \& 
Folk (I955) have described lesions involving the buccal, lingual and proximal surfaces in addition to the occlusal fissures of the rat molars. In our animals we have observed occlusal lesions only.

The object of this preliminary study was to find out if a caries-susceptible colony could be built up from a few individuals imported from an established susceptible colony.

We were successful in producing a marked degree of caries in our animals after they had been maintained on the high-sugar diet for 6 months. This is a much longer time than is necessary in the original Harvard colony.

\section{EXPERIMENTAL}

Animals. Six pairs of rats were transported by air from Boston, Mass., U.S.A., to this country. They were from the caries-susceptible colony at the Harvard School of Dental Medicine and had been maintained on a diet containing $67 \%$ sucrose (Shaw, 1950). During their journey they had access to the sugar diet and to raw potato. On arrival in our laboratory they were placed on a stock diet of Lever cubes, known to be an adequate diet for the albino rat (Hartles, 195I). At this stage it was inadvisable to expose the animals to the risk of a synthetic diet that could not be identical with the one they had been receiving. We preferred to raise the first litters on a stock diet. The animals were allowed a period of 2 weeks in which to become acclimatized; five pairs were then mated. One of the females died before full term but the others had satisfactory litters and between them produced twenty female and fourteen male offspring. Second litters were obtained after a resting period of I month. All the young were maintained on the cube diet until they were Ioo days old. At this age eighteen females were distributed into sets of six and mated. One set was placed on the high-sugar diet at mating, the young were weaned on to the diet and maintained on it thereafter. Seventeen of these animals formed group $\mathrm{r}$. The second set received Lever cubes until parturition, then the high-sugar diet, which the young also received thereafter. Sixteen of these offspring formed group 2. The third set received Lever cubes throughout and the young never had access to the high-sugar diet. Seventeen offspring formed group 3 .

The animals of groups I, 2 and 3 were killed when they were I 19 days old.

The remaining females from the first matings were placed on the high-sugar diet and mated. Their progeny have since multiplied and the whole colony is now maintained on the sugar diet as a stock diet.

A further sixty-two animals born to parents bred and reared on the high-sugar diet were killed at intervals in an attempt to determine the time necessary to produce a degree of caries suitable for our purpose. These groups were: group 4 , ten animals killed at 106 days; group 5, twelve animals killed at 149 days; group 6, twenty-four animals killed at 184 days; group 7 , sixteen animals killed at 204 days. It would be wasteful to maintain the animals beyond the time after which few new lesions appear.

Housing. The animals were kept in galvanized-wire cages $12 \times 12 \times 6$ in. with bottoms of $\frac{3}{4}$ in. ${ }^{2}$ mesh; four or five rats were kept in one cage. The temperature of the 
animal house was maintained at $70^{\circ} \pm 5^{\circ} \mathrm{F}$. Just before parturition the females were provided with wood-wool bedding. Litters were weaned at 2 I-25 days. The weight of pups at weaning was about $30-35 \mathrm{~g}$.

Composition of the diet. The high-sugar diet ( $\mathrm{HS} \mathrm{r}$ ) was similar to the diets used by Shaw (1950), Sognnaes (1948) and Hartles (195 I), but the vitamin supplements were larger, except for the omission of inositol. The diet without supplements is shown in Table I.

Table $\mathrm{x}$. Composition of the high-sugar diet (HS I) without supplements (see Table 2)

$\begin{array}{lc} & \mathrm{g} / \mathrm{kg} \\ \text { Sucrose (icing sugar, Tate and Lyle Ltd) } & 670 \\ \text { Casein, soluble (Evans Medical Supplies Ltd) } & 200 \\ \text { Hepamino (see below) (Evans Medical Supplies Ltd) } & 40 \\ \text { Groundnut oil (J. Bibby and Sons Ltd) } & 50 \\ \text { Salt mixture (Shaw et al. 1944) } & 40\end{array}$

To r $\mathrm{kg}$ of diet the supplements (Shaw's (r950) figures for $1040 \mathrm{~g}$ diet are included for comparison) shown in Table 2 were added.

Table 2. Supplements added to I kg of diet $H S_{\mathrm{I}}$ with, for comparison, the supplements added by Shaw (1950) to 1040 g of his diet

\begin{tabular}{|c|c|c|}
\hline & $\begin{array}{l}\text { Diet } \\
\text { HS x } \\
(\mathrm{mg})\end{array}$ & $\begin{array}{l}\text { Diet of } \\
\text { Shaw } \\
(1950) \\
\text { (mg) }\end{array}$ \\
\hline Thiamine hydrochloride & 15 & 3.5 \\
\hline Riboflavin & I 5 & $3 \cdot 5$ \\
\hline Pyridoxin hydrochloride & 5 & $3 \cdot 5$ \\
\hline Nicotinamide & 25 & 25 (nicotinic acid) \\
\hline Calcium pantothenate & 25 & 20 \\
\hline p-Aminobenzoic acid & 500 & 300 \\
\hline Choline chloride & I 500 & 1000 \\
\hline Inositol & - & 1000 \\
\hline Vitamin $\mathrm{A}$ acetate & 20 & I I $(\beta$-carotene $)$ \\
\hline DL- $\alpha$-Tocopheryl acetate & 300 & $5 \circ(\alpha$-tocophero 1$)$ \\
\hline 2-Methyl-I : 4-naphthoquinone & 20 & 6 \\
\hline Ergocalciferol & $200 \mu \mathrm{g}$ & $\begin{array}{l}3000 \text { i.u. } \\
\text { (irradiated ergosterol) }\end{array}$ \\
\hline
\end{tabular}

According to the makers' specification $40 \mathrm{~g}$ Hepamino should include the following accessory food factors: thiamine 0.4 , riboflavin $5 \cdot 2$, pyridoxin $0 \cdot 8$, folic acid $\mathrm{I} \cdot 2$, biotin 0.16 , inositol 100 , nicotinic acid 34 and cyanocobalamin $0.24 \mathrm{mg}$. The Hepamino also contributed one-sixth of the total protein in the diet. Shaw (1950) used equal quantities $(2 \%)$ of whole liver and of a liver concentrate in his diet. He used maize oil whereas we used groundnut oil. Both oils contain adequate quantities of the unsaturated fatty acids.

Preparation of the diet. The solid components of the diet were all in a finely powdered state. The icing sugar and casein particles were sufficiently small without further treatment. The salt mixture was ground in a mechanical mortar until it all passed through a 6o-mesh sieve. The Hepamino, which is a proteolysed whole-liver preparation, is in the form of friable crumbs and is easily ground to a fine powder in a hand mortar. 
The groundnut oil (containing the fat-soluble vitamins) was added to the casein and thoroughly worked in. The remaining dry components were added and thoroughly mixed. The water-soluble vitamins were mixed with water so that $20 \mathrm{ml}$. contained the vitamins necessary for $\mathrm{I} \mathrm{kg}$ of diet. The $p$-aminobenzoic acid was converted to its sodium salt with the calculated amount of sodium carbonate. The vitamin solution was added to the diet and thoroughly mixed. Water $(c .60 \mathrm{ml}$.) was added to the mixture so that it would just hold together when squeezed firmly in the hand. The diet was never wet or sloppy. Not more than 2 days' supply was made at a time. The animals received fresh diet daily.

Amount of food consumed. The diet was provided in 2 oz. glass pots which were clipped on to the inside of the cage. Each pot stood on a circular metal tray (diameter 4 in.) with $a \frac{1}{4}$ in. raised rim which minimized the loss of food by scattering. The animals were fed each morning and the pots replenished in the late afternoon if necessary. The rats therefore received as much food as they could eat; usually ro- $15 \mathrm{~g}$ daily was consumed by each animal. The diet was acceptable over long periods, there being no falling off in demand.

Drinking water. Tap water was provided from drinking bottles with glass spouts.

Excreta. The faeces were small, black and dry, the diet appeared therefore to be well utilized. After 6 weeks on the régime some of the animals exhibited slight glycosuria.

Examination of the molar teeth. At the end of the experimental period the animals were killed with ether. The heads were removed and boiled for $30 \mathrm{~min}$ in soap solution. The soft tissues were then removed from the jaws with forceps and finally by brushing with a tooth brush. The teeth were examined under a low power $(\times$ Io) binocular microscope.

The normal rat molar (see P1. I, I) exhibits on its occlusal surface several deep fissures lined with enamel. In this investigation caries appeared to begin only in the deepest part of a fissure. In most animals on the HS I diet, food particles, faeces and hair became impacted in the fissures. The impacted material was usually brown in colour. Where there was no caries the enamel remained unstained and retained its normal glistening appearance.

The earliest visible sign of a carious attack seemed to be a brownish staining of the walls of the fissure and a loss of translucency in the enamel without apparent loss of tooth substance (P1. I, 2). Ground sections were prepared from a typical lesion at this stage. These showed (Pl. I, 3) that the enamel on the lateral walls of the fissure was affected over a considerable area and that near the base of the fissure there was a breach in the enamel communicating with the dentine. The underlying dentine showed considerable staining and, as a result of the boiling and drying process to which the teeth had been subjected, the demineralized layer adjacent to the enamel had contracted leaving a narrow space at the amelo-dentinal junction. In view of these findings it appears entirely justifiable to consider this type of lesion as being caries.

In more advanced lesions there was obvious and progressive destruction of both enamel and dentine producing large irregular cavities in the tooth (Pl. 2, I, 2).

Scoring of the carious lesions. No elaborate scoring procedure was adopted. If more than one-quarter of the crown was destroyed the tooth received a score of 3 . If the loss 
of tooth substance was obvious but involved the destruction of less than one-quarter of the crown it was scored 2. If the tooth had an early lesion (as described above), not involving visible loss of tooth substance, it was scored I. An intact tooth was scored 0 . Results were expressed both as average number of carious teeth per animal and as average caries score per animal.

\section{RESULTS}

\section{Performance of the animals}

General condition. Occasional animals amongst the first litters, both on the Levercube diet and on the sugar diet, developed superficial abscesses in the axillary region. These, if left, burst and were cleaned up by the animal with no apparent ill effects. Examination of the thick green pus showed it to be primarily due to an infection with Bacillus friedländer. No such infection occurred in subsequent generations.

The general health was excellent, the animals had a good muscle tone, were lively and strong. Four animals in one cage developed a temporary baldness of the head and neck, but otherwise the coats were good. Occasionally an animal developed a sore eye which responded to treatment with boric-acid solution.

Growth. The growth of the animals was equally as good on the HS I diet as on the Lever-cube diet. For groups I, 2 and 3 the mean final body-weight ( 19 days) and mean growth rates of the animals were as shown in Table 3 . Reproduction on diet HS $\mathbf{I}$ was satisfactory, an average of six to seven pups per litter being reared.

Table 3. Growth of animals on the $H S_{\mathrm{I}}$ and on the Lever-cube diets

\begin{tabular}{|c|c|c|c|c|}
\hline \multirow[b]{2}{*}{ Group } & \multicolumn{2}{|c|}{ Females } & \multicolumn{2}{|c|}{ Males } \\
\hline & $\begin{array}{l}\text { Final } \\
\text { body- } \\
\text { weight } \\
(\mathrm{g})\end{array}$ & $\underset{\text { (g/day) }}{\text { Gain }}$ & $\begin{array}{c}\text { Final } \\
\text { body- } \\
\text { weight } \\
(\mathrm{g})\end{array}$ & $\begin{array}{c}\text { Gain } \\
\text { (g/day) }\end{array}$ \\
\hline I $(\mathrm{HS} I)$ & 170 & $I \cdot 4$ & 239 & $2 \cdot 2$ \\
\hline $2\left(\mathrm{HS}_{1}\right)$ & 181 & $1 \cdot 6$ & 242 & $2 \cdot 2$ \\
\hline 3 (Lever cubes) & 191 & $1 \cdot 6$ & 243 & $2 \cdot I$ \\
\hline
\end{tabular}

\section{Condition of teeth}

Group I. There were no obvious signs of caries, one or two of the lower first molars had slightly discoloured fissures. The teeth showed no evidence of attrition, the cusps were all intact and showed no sign of fracture (P1. I, I). The fissures were often filled with debris of diet, faeces and hair. There were in some animals accretions on the smooth buccal, distal and lingual surfaces of the upper (particularly the first) molars.

Group 2. The results were similar to those for group I.

Group 3. There was no evidence of caries but there was considerable attrition of the occlusal surfaces. As a consequence there was less adventitious material adhering to the teeth (Pl. 2, 3).

Group 4. There was no evidence of caries.

Group 5. Caries was observable in six of the twelve animals. Only one animal had grossly carious molars. Results are given in Table 4 . 
Group 6. There was a definite increase in both incidence and severity of lesions compared with group 5 (see Table 4); sixteen of the animals had carious teeth.

Group 7. Caries occurred in twelve rats. There was an increase in the number of lesions per animal and in their severity compared with group 6 (see Table 4).

Table 4. Development of caries in rats on a high-sugar diet $(H S \mathrm{I})$

\begin{tabular}{|c|c|c|c|c|c|c|c|c|c|c|c|}
\hline \multirow[b]{2}{*}{$\begin{array}{c}\text { Group } \\
\text { no. }\end{array}$} & \multirow{2}{*}{$\begin{array}{c}\text { No. } \\
\text { of } \\
\text { rats }\end{array}$} & \multirow{2}{*}{$\begin{array}{l}\text { Age at } \\
\text { killing } \\
\text { (days) }\end{array}$} & \multirow{2}{*}{$\begin{array}{c}\text { No. of } \\
\text { rats } \\
\text { with } \\
\text { caries }\end{array}$} & \multicolumn{4}{|c|}{ No. of carious teeth } & \multicolumn{4}{|c|}{ Caries score* } \\
\hline & & & & Total & $\begin{array}{l}\text { Per } \\
\text { rat }\end{array}$ & $\underset{\text { mandible }}{\text { Per }}$ & $\begin{array}{c}\text { Per } \\
\text { maxilla }\end{array}$ & Total & $\begin{array}{l}\text { Per } \\
\text { rat }\end{array}$ & $\begin{array}{c}\text { Per } \\
\text { mandible }\end{array}$ & $\begin{array}{c}\text { Per } \\
\text { maxilla }\end{array}$ \\
\hline 4 & 10 & 106 & 0 & 0 & o & 0 & 0 & 0 & 0 & 0 & 0 \\
\hline 5 & I2 & 149 & 6 & 16 & $1 \cdot 3$ & 10 & 0.3 & 25 & $2 \cdot 1$ & I.4 & 0.7 \\
\hline 6 & 24 & 184 & 19 & 53 & $2 \cdot 2$ & 1.9 & 0.3 & 89 & 3.7 & $3 \cdot 3$ & 0.4 \\
\hline 7 & 16 & 204 & 12 & 39 & $2 \cdot 4$ & $2 \cdot 2$ & 0.2 & 74 & $4^{\cdot 6}$ & $4 \cdot 2$ & 0.4 \\
\hline
\end{tabular}

\section{DISCUSSION}

The results show that our animals maintained on diet HS r did not develop any measurable dental caries until they were 149 days old, the average number of carious teeth at this age being $\mathrm{I} \cdot 3$. This figure must be taken cautiously since it was raised by the inclusion of one rat with extensive caries. At 184 days of age there was a considerable increase in caries, the average number of affected teeth per animal rising to $2 \cdot 2$. In accordance with the results of many other workers it was found that the teeth of the mandible were very much more susceptible to decay than those of the maxilla. The first and second mandibular molars were more frequently carious than the third molars. After 204 days on the diet there was a further slight increase in the number of carious teeth per animal $(2 \cdot 4)$. It would appear, therefore, that in the conditions of this investigation the rats must be maintained on diet HS I until they are about 6 months old before a degree of caries adequate for experimental purposes is produced. This is a longer time than is necessary to produce caries in the parent Harvard colony. Shaw (1950) reports extensive caries after 3-4 months on a high-sugar diet.

Effect of Lever-cube diet fed to rats for one generation. In view of the work of Sognnaes (1948) it might have been expected that one result of the interruption of the highsugar diet for one generation would be a lowered susceptibility to dental caries in the next generation (group 2). That this reduced susceptibility should persist in animals of subsequent generations (groups $4-7$ ) was unexpected.

There is no obvious explanation why our rats should be less susceptible to caries than the parent colony. Our results emphasize, however, the dangers of comparing findings of different laboratories since small changes in the diet or a change in environment may influence the susceptibility to dental caries.

The degree of caries found in our animals is, however, sufficiently large to enable them to be used in the study of dietary factors in relation to experimental rat caries. 


\section{SUMMARY}

I. Dental caries has been produced in a colony of rats bred from four pairs of animals imported from the caries-susceptible colony at Harvard University School of Dental Medicine, Boston, Mass.

2. The animals were fed on a purified diet containing $67 \%$ sucrose.

3. Growth, reproduction and lactation on the high-sugar diet were good.

4. After 184 days an average of $2 \cdot 2$ carious teeth per animal was observed.

The authors are greatly indebted to Dr J. H. Shaw of the Harvard School of Dental Medicine for providing the animals from which this colony has been bred.

Grateful thanks are due to Messrs J. Bibby and Sons Ltd for the gift of groundnut oil; to Evans Medical Supplies Ltd for the gift of Hepamino; and to Messrs Tate and Lyle Ltd for the gift of icing sugar.

The authors also wish to thank Mr R. P. Williams for his care and maintenance of the animals, and Mr J. S. Bailie for the photography.

\section{REFERENCES}

Cox, G. J., Dodds, M. L., Levin, M. M. \& Hodge, H. C. (1948). Э. dent. Res. 27, 562.

Hartles, R. L. (195I). Biochem. F. 48, 245.

Hoppert, C. A., Webber, P. A. \& Canniff, T. L. (1932). 7. dent. Res. r2, I6I.

King, J. D. (I935). Brit. dent. F. 59, 233.

McClure, F. J. (1945). F. dent. Res. 24, 239.

McClure, F. J. \& Folk, J. E. (1955). F. dent. Res. 34, 358.

Shaw, J. H. (1950). F. Nutr. 4I, I3.

Shaw, J. H., Schweigert, B. S., McIntyre, J. M., Elvehjem, C. A. \& Phillips, P. H. (I944). F. Nutr. 28, 333 .

Sognnaes, R. F. (1948). F. Amer. dent. Ass. 37, 676.

Stephan, R. M. (195I). $\mathscr{F}$. dent. Res. 30, 484 .

\section{EXPLANATION OF PLATES}

Illustrations of mandibular molars from the experimental groups of rats.

\section{Plate I}

r. Occlusal view of molar from group 1 , deemed to present a normal picture. $\times 9$.

2. Early carious lesion in second molar corresponding to the ground section shown in Pl. $1,3(b) . \times 9$.

3. Ground section through a fissure of molars. $\times$ I20. (a) Normal fissure filled with food debris and faeces. (b) Early caries, showing that the enamel on the lateral walls is affected; near the base of the fissure there is a break in the enamel communicating with the dentine.

\section{Plate 2}

I. Carious lesions in the first and third molars, typical of cavities scored 2, i.e. visible tooth destruction involving loss of less than one-quarter of the crown. $\times 9$.

2. Carious lesions in the first molar typical of a cavity scored 3 , i.e. destruction of more than one-quarter of the crown. $\times 9$.

3. Attrition: the crowns are almost completely worn away. This degree of attrition was found only in animals receiving the Lever-cube diet. $\times 9$. 
R. L. HARTLES, F. E. LAWTON AND G. L. SLACK.

DENTAL CARIES IN RATS ON A HIGH SLGAR DIET
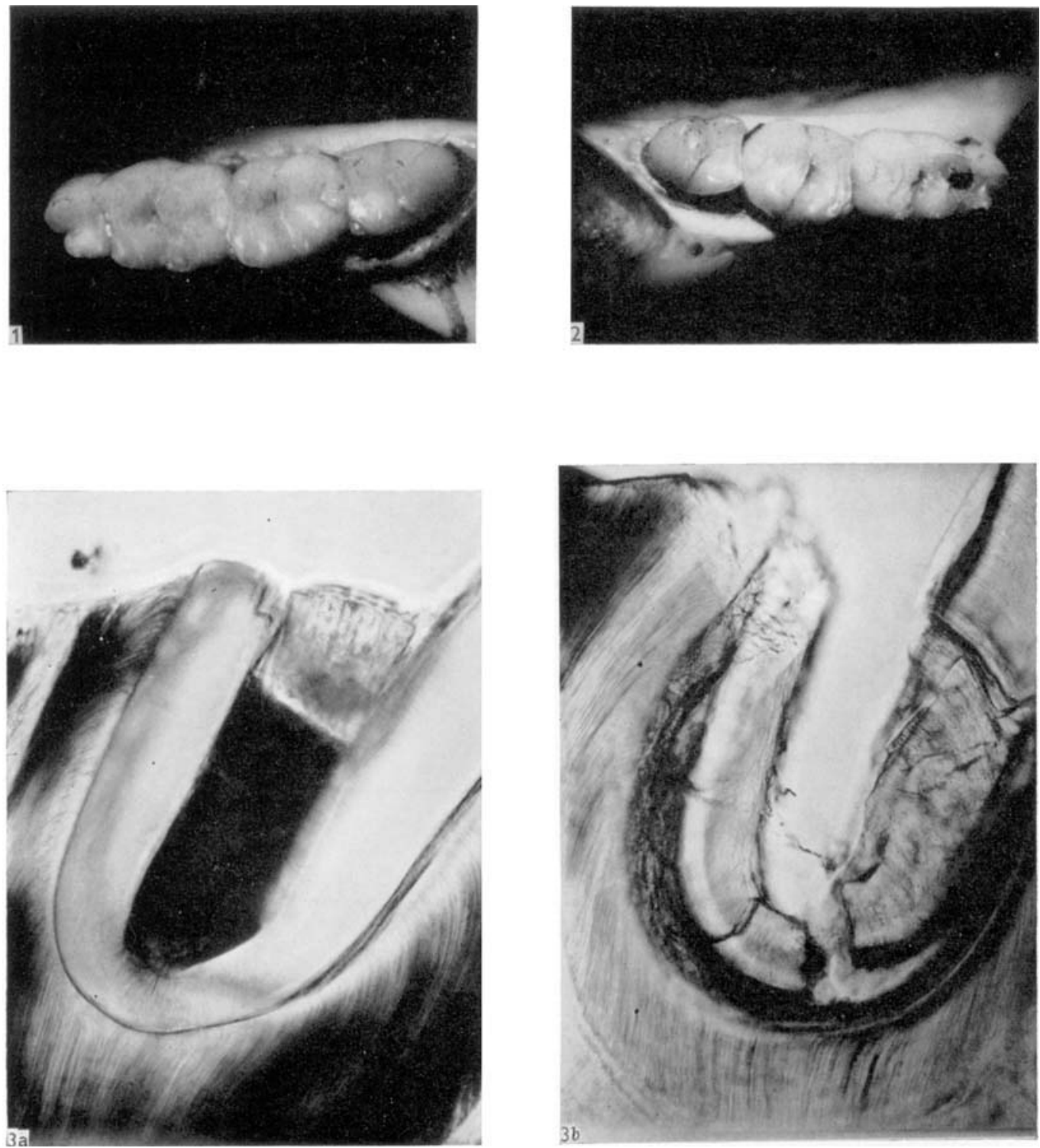

British Fournal of Nutrition, Vol. 10, No. 3 
R. L. HARTLES, F. E. LAWTON AND G. L. SLACK.

Plate 2

DENTAL CARIES IN RATS ON A HIGH-SUGAR DIET

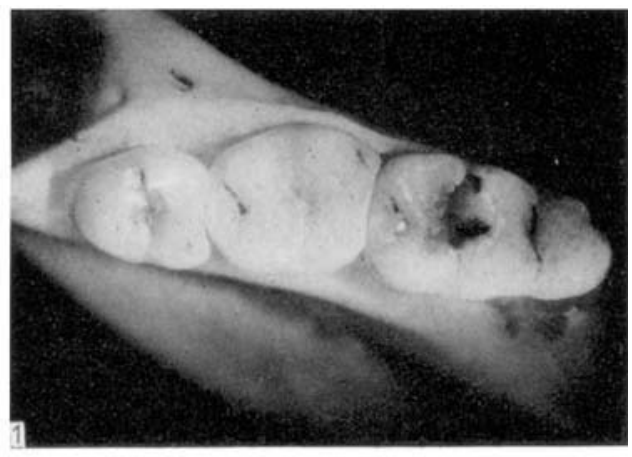

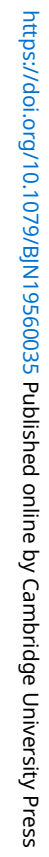
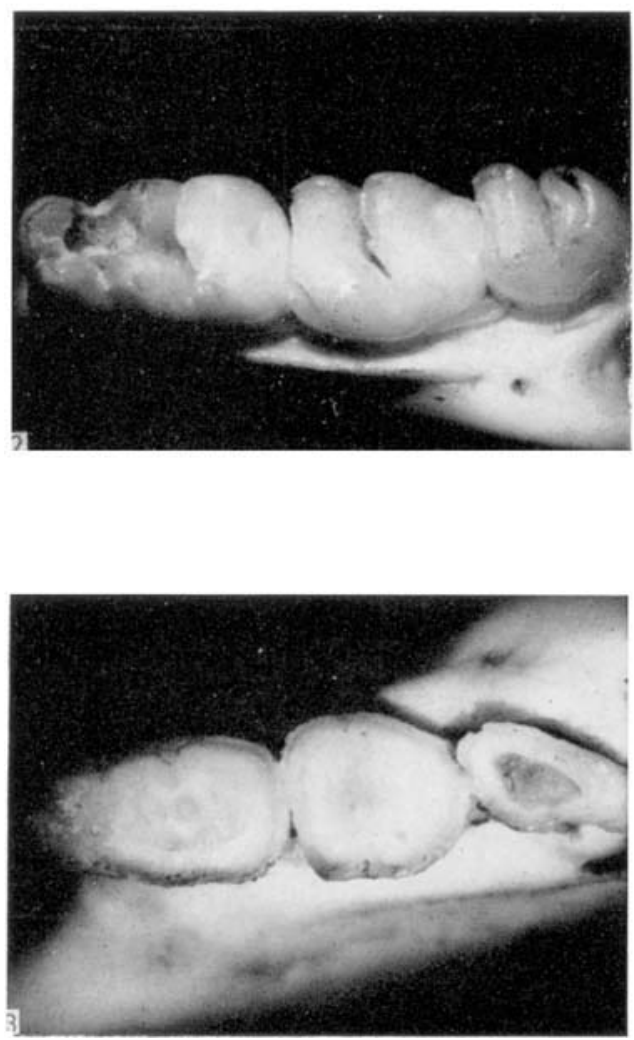

British Fournal of Nutrition, Vol. 10, No. 3 